\title{
Propuesta de una batería de test para la evaluación física del kayak-polo Specific test to Canoe Polo
}

\author{
*Fernando Alacid Cárceles, **Gema Torres Luque \\ *Universidad de Murcia (España), **Universidad de Jaén (España)
}

\begin{abstract}
Resumen: La creación de test o baterías de test cada vez más específicas está contribuyendo a un mejor conocimiento del deportista y a la consecución del máximo rendimiento deportivo. De esta forma, a partir del análisis de las características de una especialidad deportiva como es el kayak-polo, el objetivo de este trabajo es proponer una batería de seis test específicos, así como la propuesta metodológica para llevarla a cabo. Esta batería de test está compuesta por las siguientes pruebas: lanzamiento de balón medicinal de $3 \mathrm{~kg} ; 15$ m máximos con salida; test de 5 x 10 m; test de 20 x 20 m; valoración de la frecuencia cardiaca en juego y conducción de balón en zigzag.
\end{abstract}

Palabras clave: Kayak Polo, test, entrenamiento.

Abstract: The creation of specific test or batteries of test are contributing to increase the knowledge of the sportsmen/women and to achieve the maximum sports performance. From the analysis of the characteristics of a sport like canoe polo, the aim of this paper is to propose a battery of test for canoe polo, as well as the method to carry out it. The battery of test is composed by the following test: throwing a ball of $3 \mathrm{~kg} ; 15 \mathrm{~m}$ test; $5 \mathrm{x} 10$ $\mathrm{m}$ test; 20 × $20 \mathrm{~m}$ test; and finally driving in zigzag.

Key words: Kayak Polo, testing, canoeing, training.

\section{Introducción}

En nuestros días el entrenamiento deportivo es un entramado complejo que conlleva un trabajo multidisciplinar y coordinado. Si se pretende obtener el máximo rendimiento deportivo, son diferentes los recursos humanos que son necesarios en este trabajo en conjunto. Los avances en el conocimiento, tecnologías y técnicas en el entrenamiento deportivo experimentados en las últimas décadas han hecho que, de forma paralela, se hayan producido notables progresos en todos los aspectos que definen la valoración funcional y biológica del deportista.

En este sentido, la utilización de test, es una práctica habitual en el control del entrenamiento deportivo. Los test valoran una capacidad o cualidad física en concreto, mientras que la batería de test es un grupo de test que intenta valorar el estado de forma del deportista. En un primer momento, las baterías de test se crearon con el objetivo de valorar el estado de forma de cualquier persona, deportista o no, siendo una delas más conocidas la Batería Eurofit (Consejo de Europa, 1987).

A partir de la creación de este tipo de baterías generales, la propia evolución del entrenamiento y la planificación deportiva, así como la especialización temprana a nivel deportivo, crea la necesidad de realizar test o baterías de test específicos para cada especialidad. La búsqueda del máximo rendimiento deportivo, pasa por un análisis exhaustivo del deporte, para con ello crear pruebas específicas que indiquen el nivel de performance para esa actividad y no otra.

Son diferentes los autores que han propuesto valoraciones específicas para diferentes especialidades deportivas. Con ello, se consigue crear un perfil del deportista con un nivel muy alto de especificidad. Así, se han creado test como el Special Judo Fitness Test, que valora a los judokas específicamente en el tatami (Sterkowics, 1995), pudiendo crear de esta forma baremos según categoría y edad, y ver quiénes son los judokas que se aproximan más a las características de los judokas de elite. Otras especialidades deportivas tienen baterías de test, como por ejemplo el waterpolo, donde Falk, Lidor, Lander, \& Lang (2004) crearon una batería especifica de ocho pruebas, y realizaron un seguimiento a 24 waterpolistas para ver la evolución con esas pruebas concretas realizadas en la propia piscina. Del mismo modo, en un deporte como el balonmano son diversos los autores que proponen pruebas de valoración especificas para este deporte, y con ello contribuir a la selección de talentos (Lidor et al., 2005; Moreno, 2004). Incluso en un estudio de

Fecha recepción: 28-10-08 - Fecha envío revisores: 28-10-08 - Fecha de aceptación: 11-11-08 Correspondencia: Fernando Alacid Cárceles

Calle Argentina, $s / n$.

30720 Santiago de la Ribera (Murcia)

E-mail: fernando.alacid@um.es
Keogh, Weber, \& Dalton (2003) abordaron un conjunto de test que abordaban distintas áreas de conocimiento, con el objetivo de identificar talentos deportivos en esta especialidad y en el género femenino en concreto.

Por lo tanto, si se quieren determinar las características específicas sobre el rendimiento de un deportista, debe hacerse en base a un conjunto de test que valoren esa actividad de forma concreta.

De esta forma, el objetivo de este trabajo es proponer una batería de test para una especialidad deportiva como el kayak-polo, y con ello, contribuir con una herramienta que permita determinar el nivel de performance de este deporte.

\section{Antecedentes históricos}

El Kayak Polo es considerado la disciplina de crecimiento más rápido en elámbito del piragüismo (McCusker, 2002). Sin embargo, sus orígenes son diversos según se describe en la poca bibliografía disponible. Entre 1875 y 1884 se publicaron en revistas británicas fotos en las que aparecían juegos acuáticos de pelota sobre diferentes artefactos flotantes (barriles, plataformas), siendo en 1884 la publicación de una foto en la revista The Graphic (figura 1) el antecedente más parecido al Kayak Polo actual al ser jugado sobre kayaks de madera (Beasley, 2007). Posteriormente, en Alemania entre 1920 y 1930 se desarrolló como actividad lúdica y antes de la segunda guerra mundial ya se disputaban campeonatos nacionales (De Bergia, 1993). En el Canoe Club de Francia jugaban con una pelota sobre canoas a un juego que llamaban canoe ball hasta que en 1943 empezaron a usar kayaks y redactaron el reglamento del kayak ball (Beasley, 2007). McCusker (2002) indica su uso por los palistas de slalom en aguas bravas del Reino Unido como medio de entrenamiento técnico durante el invierno en piscinas climatizadas, siendo la Federación Británica (British Canoe Union), la principal precursora del juego en la versión más parecida a la actual, principalmente por la minimización del tamaño de las embarcaciones y la elevación de la portería (Byde, 1973). Desde 1952 se jugaba en Australia a un juego de pelota sobre canoas dobles, mientras que el palista de proa manejaba el móvil, el de popa se encargaba de dirigir la embarcación (Beasley, 2007).

Los diferentes orígenes del juego, provocaron multitud de variaciones en cuanto al reglamento. EnAlemania, Italia y Holanda se jugaba en campos de dimensiones de hasta $80 \mathrm{~m}$ de largo, las porterías se encontraban sobre el agua y únicamente se podía utilizar la pala para manejar la pelota, mientras que en el Reino Unido, Francia y Australia se jugaba en campos más pequeños (piscinas), la portería era un cuadrado de $1 \mathrm{~m}$ de lado suspendida $2 \mathrm{~m}$ sobre el agua y la pelota podía ser jugada con las manos (Beasley, 2007). 


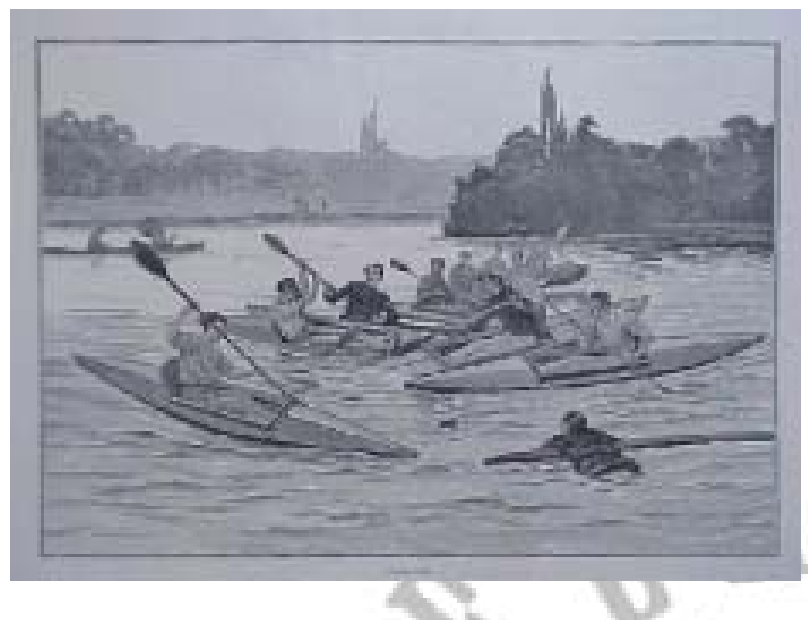

Figura 1. Imagen de The Graphic 1884 (Tomada de Beasley, 2007 por cortesía de J W Lester)

En 1986, la Federación Internacional de Piragüismo (International Canoe Federation), publicó su primer borrador del reglamento oficial, realizándose el primer torneo de exhibición en 1987 en Duisburg (Alemania) simultáneamente al Campeonato del Mundo de Aguas Tranquilas. El primer reglamento oficial fue finalizado en $1990 \mathrm{y}$ el primer Campeonato del Mundo de Kayak Polo se celebró en Sheffield (Inglaterra) en 1994, con una participación de 16 países en la categoría masculina y 6 en la femenina.

En España, fue introducido en la década de 1970, desarrollándose en todo el territorio nacional en la de los 90 (Gómez, 2000). Actualmente, se disputan varias ligas: en la categoría masculina, primera y segunda división absoluta, primera división sub-21 y de ascenso a segunda división; mientras que en la categoría femenina únicamente existe competición de primera división. Cada liga está formada por 10 equipos y se disputan en forma de torneos, siendo cuatro los disputados por la primera y segunda división masculina absoluta y tres para el resto.

\section{Las normas del juego}

Según su reglamento, el Kayak Polo consiste en un juego de pelota competitivo entre dos equipos, compuestos de cinco jugadores cada uno. Los participantes, provistos de un kayak y de una pala, intentan marcar goles en la portería del contrario (RFEP, 2007).

Elárea de juego es una lámina de aguas tranquilas de forma rectangular y con unas dimensiones de $35 \mathrm{~m}$ de largo, $23 \mathrm{~m}$ de ancho y $0.90 \mathrm{~m}$ de profundidad mínima. Los límites del área de juego se delimitan mediante corcheras. Sobre las líneas de meta, se encuentran las porterías suspendidas a $2 \mathrm{~m}$ sobre la lámina de agua, éstas poseen $1 \mathrm{~m}$ de alto por $1.5 \mathrm{~m}$ de ancho. La pelota utilizada es similar a la de water-polo.

Los jugadores van provistos de un kayak de 2.10 a $3.10 \mathrm{~m}$ de longitud y 0.50 a 0.60 de anchura, una pala de hasta $2.20 \mathrm{~m}$ de largo, un cubrebañeras para evitar que entre agua en el interior de la embarcación, un protector corporal de forma similar a un chaleco salvavidas y un casco con protector facial, habitualmente con forma de rejilla.

La pelota se puede manejar con la mano, la pala e incluso con la embarcación, siendo lo más habitual y preciso el uso de las manos en los lanzamientos, recepciones y conducción del móvil. Una de las normas más características del juego es que la posesión está limitada a cinco segundos, y durante la misma el jugador en posesión puede ser empujado del costado o la espalda por otro palista incluso hasta conseguir el vuelco del primero.

Los partidos de Kayak Polo comienzan de forma similar a los de water-polo, con el lanzamiento de la pelota, por parte de uno de los árbitros, al centro del campo y la disputa de la posesión inicial del mismo. Previamente, los jugadores se encuentran sobre la línea de meta defensiva. Se disputan dos períodos de 10 minutos cada uno, con un descanso intermedio de 3 minutos. En caso de empate se recurre a jugar períodos adicionales o lanzamientos de desempate.

\section{Test específicos para Kayak Polo}

Existen multitud de tests complementarios que se pueden realizar a cualquier practicante de deportes colectivos, y cada uno de ellos, puede resultar de una gran utilidad para la valoración de las diferentes capacidades necesarias en su deporte. En este caso, nos centraremos en pruebas de evaluación de la condición física en el agua y en el dominio técnico de la embarcación y la pelota.

\subsection{Lanzamiento de balón medicinal de $3 \mathrm{~kg}$.}

Objetivo: Valorar la fuerza explosiva del palista en el lanzamiento.

Descripción: El palista sentado en su propia embarcación, situada fuera del agua, lanzará un balón medicinal de $3 \mathrm{~kg}$. de peso con el brazo dominante, el no dominante y con ambos desde el pecho. Se medirá el lanzamiento desde la proa de la embarcación.

\section{2. $15 \mathrm{~m}$ máximos con salida.}

Objetivo: Valorar la velocidad de aceleración y de desplazamiento en la salida.

Descripción: Partiendo de parado, el palista recorrerá a intensidad máxima la distancia de $15 \mathrm{~m}$. Mediante el posterior análisis de vídeo se determinarán los tiempos de paso a los 3, 7.5 y $15 \mathrm{~m}$.

\subsection{Test de $5 \times 10 \mathrm{~m}$.}

Objetivo: Valorar la resistencia a la velocidad del palista.

Descripción: Desde parado, el palista completará 50 m, ciabogando alrededor de dos boyas distanciadas $10 \mathrm{~m}$. Mediante el posterior análisis de vídeo se valorará la evolución de la velocidad a lo largo de la prueba. Las ciabogas serán alternativamente hacia la izquierda y hacia la derecha.

\subsection{Test de $20 \times 20 \mathrm{~m}$}

Objetivo: Valorar la capacidad láctica del palista.

Descripción: Desde parado, el palista completará 400 m, ciabogando alrededor de dos boyas distanciadas $20 \mathrm{~m}$. Mediante el posterior análisis de vídeo se valorará la evolución de la velocidad a lo largo de la prueba. Las ciabogas serán alternativamente hacia la izquierda y hacia la derecha. Al final de la prueba se realizará una toma de lactato y en los minutos $1,3,5$ y 7.

\subsection{Frecuencia cardiaca en juego.}

Objetivo: Valorar la evolución de la frecuencia cardiaca a la largo de una situación de juego real.

Descripción: Se registrará la evolución de la frecuencia cardiaca en una situación de juego real. Se realizará paralelamente una grabación para comparar las diferentes acciones de juego con los valores de frecuencia cardiaca registrada.

\subsection{Conducción de balón en zig-zag.}

Objetivo: Valorar la capacidad de maniobra y manejo del balón.

Descripción: Desde parado, el palista completará el circuito de la figura 2 en el menor tiempo posible mediante autopases. Se saldrá desde el borde de la piscina y el tiempo se pondrá en marcha cuando la proa pase por la primera boya y se detendrá al finalizar el recorrido al pasar por la misma boya.

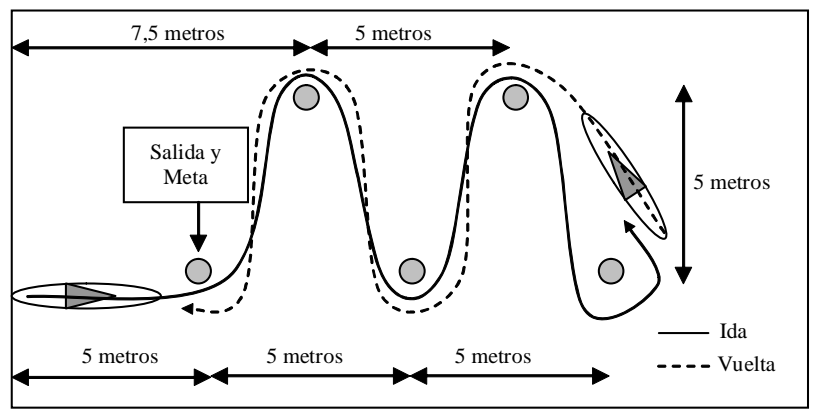

Figura 2. Esquema del test de conducción de balón en zig-zag. 


\section{Análisis de video}

Es necesario realizar la grabación lateral de las pruebas de agua (15 m, 5 x 10 m y 20 x 20 m) desde el lateral contrario de la piscina a la realización del test. Para la posterior obtención de tiempos parciales, deben colocarse boyas como sistema de referencia, indicando la salida, $3 \mathrm{~m}, 7.5 \mathrm{~m}$ y llegada en el test de $15 \mathrm{~m}$, y la ciaboga en los test de $5 \times 10$ m y 20 x 20 m. La metodología utilizada es similar a la empleada en estudios para la determinación de la evolución de las variables cinemáticas en piragüismo de aguas tranquilas (Alacid, Ferrer, Martínez, \& Carrasco, 2005; Alacid et al., 2008; Sperlich \& Baker, 2002).

Para la reproducción de las grabaciones se utiliza el VirtualDub Portable 1.6.19 by Avery Lee donde se puede observar el fotograma correspondiente a cada una de las imágenes visualizadas. Las grabaciones son obtenidas a 25 fotogramas por segundo. En el registro y obtención de los datos se puede utilizar una hoja de cálculo Microsoft Excel XP (Microsoft Corporation, EE.UU.).

En el test de $15 \mathrm{~m}$, se debe tomar como señal de salida el primer movimiento de tracción del palista, eliminando la influencia del tiempo de reacción sobre el resultado de la prueba. Para determinar los tiempos parciales y el total, se tomará el fotograma en el que la proa de la embarcación pasa entre las dos boyas que marcan cada una de las distancias de referencia, y se restará el número de este fotograma al establecido como salida. Tras dividir el resultado entre 25, obtendremos el tiempo empleado en recorrer la distancia a evaluar en segundos.

En el resto de test, se tomarán los tiempos parciales antes de realizar cada una de las ciabogas necesarias para cubrir la distancia, justo en el momento en que la proa pasa por la boya utilizada como referencia. La metodología para determinar los tiempos de paso es similar a la utilizada en el test de $15 \mathrm{~m}$. Usaremos el mismo fotograma para determinar el comienzo y el fin de cada parcial, por lo que todos los parciales llevarán incluida una ciaboga al inicio del mismo, excepto el primero que será el más rápido de todos. De esta forma, no se evaluaráúnicamente la velocidad de desplazamiento en condiciones de fatiga, sino también la capacidad de ciabogar rápidamente en estas condiciones. $=3 / 2$.

La frecuencia de ciclo se obtiene tras contar los ciclos completos realizados en el tramo y dividirlo entre el tiempo transcurrido en completar estos ciclos. Para determinar el tiempo transcurrido, se registraron los fotogramas en los que la hoja tomaba contacto con el agua, se calculaban los fotogramas transcurridos desde que comenzaba el primer ciclo hasta el último contabilizado y se divide el resultado entre 25 . Es importante no utilizar el primer ciclo realizado en la salida o tras una ciaboga, así como el previo a la meta o ciaboga, ya que suelen tener características diferentes a los utilizados cuando la embarcación se encuentra en la parte media de los tramos. Los resultados se obtendrán en ciclos $\cdot \mathrm{s}^{-1}$, pero si se desea, y para facilitar su comprensión, se puede realizar la conversión a paladas $\cdot \mathrm{min}^{-1}$, multiplicando el resultado por 120.

Tras obtener la velocidad y la frecuencia de ciclo, resulta sencillo valorar la longitud de ciclo. Basándonos en que la velocidad es igual a la frecuencia por la longitud de ciclo, de esta forma, longitud de ciclo es igual a velocidad dividido por frecuencia de ciclo. Para que los resultados se obtengan en metros recorridos por ciclo, es necesario expresar la velocidad en $\mathrm{m} \cdot \mathrm{s}^{-1} \mathrm{y}$ la frecuencia de ciclo en ciclos $\cdot \mathrm{s}^{-1}$.

La incertidumbre o error en la medida al digitalizar a 25 imágenes por segundo queda establecida en 0.04 segundos; mientras, el error relativo porcentual se determina dividiendo 0.04 entre el tiempo analizado, ya sea para obtener la frecuencia de ciclo o la velocidad en un tramo, y multiplicando el resultado por 100 . Se recomienda mantener los niveles de error relativo porcentual en valores inferiores al $2 \%$.

\section{Limitaciones}

La mayoría de las pruebas propuestas se centran en aspectos físicos y técnicos, en el proceso de desarrollo de esta batería de test, sería interesante desarrollar una herramienta de valoración técnico-táctica tal y como se viene realizando en otros deportes (Falk et al., 2004; Keogh et al., 2003; Lidor et al., 2005; Sterkowics, 1995; Vera, Pino, Romero, \& Moreno, 2007).

\section{Conclusiones}

Se proponen seis test específicos para un deporte poco conocido como el kayak-polo, uno de ellos relacionado con la potencia en el lanzamiento, otro con el manejo de la embarcación y el balón, tres de ellos relacionados con la velocidad del desplazamiento de la embarcación y el posterior análisis de vídeo de las pruebas y el último con la evolución de la frecuencia cardiaca en situaciones reales de juego.

\section{Referencias bibliográficas}

Alacid, F., Ferrer, V., Martínez, E., \& Carrasco, L. (2005). Análisis cuantitativo de la técnica de paleo en kayakistas infantiles. Motricidad. European Journal of Human Movement, 13, 133-146. Alacid, F., López-Miñarro, P. A., Ferragut, C., García, A., Ferrer, V., \& Martínez, I. (2008). Evolución y comparación de la velocidad, frecuencia, longitud eíndice de ciclo sobre $200 \mathrm{~m}$, en palistas infantiles de diferentes modalidades. Motricidad. European Journal of Human Movement, 20, 15-27.

Beasley, I. (2007). Boat, paddle and ball. A short history of canoe polo, [en línea]. Disponible en: http://www.canoeicf.com/site/canoeint/ if / d ownloads / Dis ciplines / C a noe \% $20 \mathrm{Pol}$ / History\%20of\%20CAP.pdf [Consulta: 2008, 15 de marzo].

Byde,A. (1973). Beginner's guide to canoeing. London: Pelham books. De Bergia, E. (1993). Reglamento de Aguas Bravas y otras disciplinas. En J. L. Sánchez (Ed.), Piragüismo (II) (pp. 334-359). Madrid: COE.

Consejo de Europa (1987). Bateria Eurofit I. Instrucciones y protocolo. 115-126.

Falk, B., Lidor, R., Lander, Y., \& Lang, B. (2004). Talent identification and early development of elite water-polo players: a 2 year followup study. Journal Sports Science, 22(4), 347-355.

Gómez, J. (2000). Kayak polo: una de las últimas novedades del piragüismo. Gaceta gymnos: Revista de educación física y deportes, 7, 9-12.

Keogh, J. W., Weber, C. L., \& Dalton, C. T. (2003). Evaluation of anthropometric, physiological, and skill-related tests for talent identification in female field hockey. Canadian Journal Applied Physiology, 28(3), 397-409.

Lidor, R., Falk, B., Arnon, M., Cohen, Y., Segal, G., \& Lander, Y. (2005). Measurement of talent in team handball: the questionable use of motor and physical tests. Journal Strength Conditioning Research, 19(2), 318-325.

McCusker, G. (2002). Canoe Polo. En F. Ferrero (Ed.), Canoe and kayak handbook (pp. 198-202). Gwynedd: Pesda Press.

Moreno, F.(2004). Balonmano. Detección, Seleccióny Rendimiento de talentos. Madrid: Gymnos.

RFEP. (2007). Reglamento de Kayak Polo, [en línea]. Disponible en: www.rfep.es [Consulta: 2008, 15 de marzo].

Sperlich, J., \& Baker, J.D. (2002). Biomechanical testing in elite canoeing. En XXth International Symposium on Biomechanics in Sports (Comp.) (pp. 44-47). Cáceres: Universidad de Extremadura.

Sterkowics, S. (1995). The Special Judo Fitness Test. Antropomotoryka, 12-13, 29-44.

Vera, G, Pino, J., Romero, C., \& Moreno, M. I. (2007). Propuesta de valoración técnico-táctica mediante una situación de juego colectivo básico en el fútbol de iniciación. Retos. Nuevas tendencias en Edu-

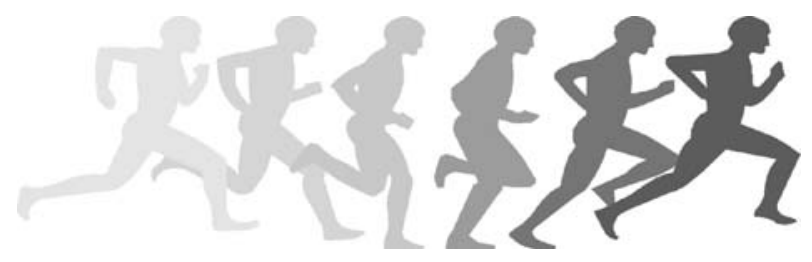

